\title{
Rapid Adsorption of Crystal Violet onto Magnetic Zeolite Synthesized from Fly Ash and Magnetite Nanoparticles
}

\author{
Olusola S. Amodu ${ }^{1,2^{*}}$, Tunde V. Ojumu1, Seteno K. Ntwampe ${ }^{3}$, Olushola S. Ayanda ${ }^{4}$ \\ ${ }^{1}$ Department of Chemical Engineering, Cape Peninsula University of Technology, Cape Town, South Africa \\ ${ }^{2}$ Department of Chemical Engineering, Lagos State Polytechnic, Lagos, Nigeria \\ ${ }^{3}$ Department of Biotechnology, Cape Peninsula University of Technology, Cape Town, South Africa \\ ${ }^{4}$ Department of Industrial Chemistry, Federal University Oye Ekiti, Oye Ekiti, Nigeria \\ Email: *os.amodu@gmail.com
}

Received 8 September 2015; accepted 4 December 2015; published 7 December 2015

Copyright (C) 2015 by authors and Scientific Research Publishing Inc.

This work is licensed under the Creative Commons Attribution International License (CC BY).

http://creativecommons.org/licenses/by/4.0/

(c) (i) Open Access

\begin{abstract}
This work reports the adsorption of crystal violet (CV) dye onto magnetic zeolite (MZ) nanoparticles, synthesized by direct fusion of fly ash (FA) and magnetite particles. The synthesised MZ showed high capacity for CV dye adsorption, removing $95 \%$ of the dye at an equilibrium adsorption time of $10 \mathrm{~min}$ and $25^{\circ} \mathrm{C}$. The effects of adsorbent dosage, dye concentration, and $\mathrm{pH}$, on adsorption were evaluated. Adsorption data were best described by the Langmuir adsorption isotherm $\left(R^{2}=0.9986\right)$, while the adsorption kinetics was best fitted by the pseudo-second-order kinetic model $\left(R^{2}=0.9999\right)$. Application of the MZs synthesised from inexpensive resources such as FA could ensure the sustainability and cost effectiveness of treating industrial effluent containing basic dyes, especially effluent from the textile industries.
\end{abstract}

Keywords

Adsorption, Crystal Violet Dye, Fly Ash, Magnetic Zeolite, Kinetics, Isotherm

\section{Introduction}

Textile industry has been listed as one of the six key industrial sectors for priority prevention and control of chemical pollutants. In spite of this, some of the chemicals that have been outlawed are still in use in the textile

"Corresponding author.

How to cite this paper: Amodu, O.S., Ojumu, T.V., Ntwampe, S.K. and Ayanda, O.S. (2015) Rapid Adsorption of Crystal Violet onto Magnetic Zeolite Synthesized from Fly Ash and Magnetite Nanoparticles. Journal of Encapsulation and Adsorption Sciences, 5, 191-203. http://dx.doi.org/10.4236/jeas.2015.54016 
industries, particularly in many developing countries. An estimated 2000 different chemicals are used in the textile industry [1]. Consequently, effluents from these industries contain organic compounds and their derivatives such as amines, ammonia, volatile organic compounds (VOCs), perfluorinated compounds, in addition to large quantities of pigments [2] [3] — some of which are recalcitrant environmental toxicants. The high concentration of chemicals and colouring agents in the effluents can adversely affect the ecosystem, causing ecological degradation when discharge without proper treatment.

Dyes are generally classified, based on their precursors, as either natural (derived from plants and animals) or synthetic (derived from organic and inorganic compounds). Synthetic dyes are relatively inexpensive, and as such, are widely used in the textile industry [4] [5]. Some are known to be toxic and potential carcinogens, containing chlorine bound organics, chromium, acetic acid, surfactants, and metals such as copper, arsenic, mercury, cobalt, lead, and cadmium [4] [6].

Crystal violet (CV) dye (Figure 1), also known as methyl violet 10B or basic violet 3, is an example of a basic synthetic dye, belonging to the group of triarylmethanes [7] [8]. The dye is hydrophilic; a property that makes it suitable for dying cellulosic fibre, silk, wool, cotton and some polyesters. The most visible effect of wastewater discharge from the textile industry is incrustation of the surface of the receiving water body, due to the pigments in the waste water. This incrustation reduces light penetration into the water, which can adversely affect marine life. Hence, effective treatment of these effluents, especially where there are stringent environmental laws in place, is paramount.

Several techniques have been used for the removal of dyes from industrial effluents, including biological (microbial decolorization, biodegradation and bioremediation), chemical (coagulation and flocculation), and physical (electrolysis, reverse osmosis, membrane-filtration, and adsorption) [9]-[12]. However, adsorption technique seems to be preferred due to its robustness in process design and scalability, couple with the fact that a plethora of renewable resources can be used for effective adsorbent synthesis. Some of these inexpensive renewable resources include sewage char and tyres, bamboo dust, coconut shell and husk, groundnut shell, rice husk and straw, oil palm shell and fibre, wheat bran, and fly ash (FA) [11] [13]-[17].

Although activated carbon is predominantly used in adsorption studies [18] [19], it has some drawbacks that can limit its application, such as flammability, ease of desorption of highly volatile adsorbates, ineffectiveness for removal of oil, grease, and organic contaminants [20] [21]. Some zeolitic materials, on the other hand, have been shown to exhibit certain advantages which include excellent ion exchange capacities, catalytic properties, easily regenerated without losing their adsorption capacities, high selectivity, etc. [22] [23]. In South Africa, for instance, zeolites synthesis from FA has received much attention due to the enormous production of the waste and the effectiveness of the zeolite produced from the waste [24]-[26]. The adsorption affinities of zeolites for organic compounds from water and wastewaters have been demonstrated [27] [28]. This apparently may be due to the magnetite composition of FA, since the application of magnetically imprinted nanoparticles have been reported for the separation of hydrocarbons and hydrocarbon derivatives, such as dyes and oil, from wastewater and minerals [20] [29] [30]. The magnetic nanoparticles of iron oxide often used in this technology are the magnetite $\left(\mathrm{Fe}_{3} \mathrm{O}_{4}\right)$ and maghemite $\left(\gamma-\mathrm{Fe}_{2} \mathrm{O}_{3}\right)$. Thus, enhancing the magnetic properties of zeolites may increase their affinity for dye adsorption.

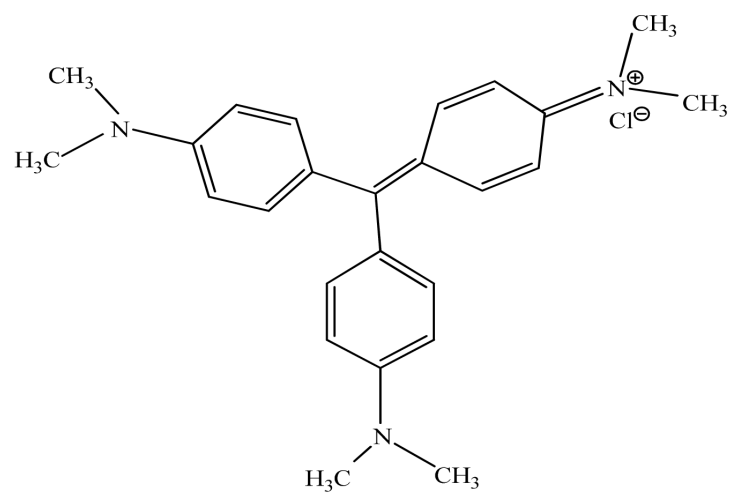

Figure 1. Chemical structure of crystal violet. 
Though some researchers have reported the adsorption of dye onto natural adsorbents [17] [20] [31], the preponderance of adsorption studies using zeolites are on metal adsorption. The aim of this work therefore was to investigate the effectiveness of magnetic zeolite nanoparticles in the removal of CV dye from wastewater. Adsorbent with highest performance was characterized with scanning electron microscopy (SEM), BET surface area analyser, and electron dispersion $\mathrm{x}$-ray spectroscopy (EDS).The adsorption isotherms and kinetics were studied. Finally, equilibrium adsorption isotherms were fitted by Langmuir and Freundlich while the adsorption kinetics was explained by the pseudo-first-order, pseudo-second-order, as well as the Elovich equation.

\section{Materials and Methods}

\subsection{Materials}

Zeolite was synthesized from FA-collected from Arnot Eskom power station, Mpumalanga, South Africa. Sodium hydroxide, hydrochloric acid, and anhydrous sodium aluminate were obtained from Sigma Aldrich, while the CV dye and magnetite $\left(\mathrm{Fe}_{3} \mathrm{O}_{4}\right)$ were obtained from Merck. All reagents were of analytical grade $(99 \%)$.

\subsection{Magnetic Zeolite Synthesis and Characterization}

The raw FA samples were first screened through a $212 \mu \mathrm{m}$ sieve to eliminate the larger particles. Mixture of sodium hydroxide, FA, and the magnetite particles, in a predetermined ratio of 1:1.5:y (by weight), respectively, was milled and fused in an oven at a temperature of $550^{\circ} \mathrm{C}$ for $1 / 2 \mathrm{~h}$ [24] [25]. The quantity of magnetite $(y)$ in this composite varied from $0.1-0.75$. The resultant fused magnetic zeolite (MZ) was then cooled to ambient temperature, milled further and dissolved in water $(1 \mathrm{~g} / 5 \mathrm{~mL}$ water). The slurry obtained was stirred at $1500 \mathrm{rpm}$ and at room temperature for $2 \mathrm{~h}$. The resultant precipitate was filtered and washed repeatedly with distilled water to remove the remaining solids. The filtrate thus obtained was mixed with $\mathrm{NaAlO}_{2}(\mathrm{aq})$ in a ratio of 2.5:1 (v/v), stirred for $20 \mathrm{~min}$ and crystallized at $100^{\circ} \mathrm{C}$ for $2-4 \mathrm{~h}$. The purpose of the addition of the aluminate solution was to control the molar ratio for a single phase zeolite synthesis. The magnetic zeolite samples synthesised were labelled $\mathrm{MZ}_{1}, \mathrm{MZ}_{2}, \mathrm{MZ}_{3}, \mathrm{MZ}_{4}$, and $\mathrm{MZ}_{5}$. However, only the sample that showed the highest adsorption capacity for $\mathrm{CV}$ dye was characterised. The BET surface area analysis was carried by first degassing the zeolite using a Micromeritics VacPrep ${ }^{\circledR} 061$ Sample Degas System (Micromeritics, USA), while a 3Flex surface characterization analyser (Micromeritics Instrument Corp., USA) was used. In addition, the morphology of the adsorbent was analysed with an S200 scanning electron micrometer (Cambridge, UK) equipped with an energy dispersive X-ray spectrometer (EDS) to determine the elemental composition of the samples.

\subsection{Adsorption Studies}

Adsorption experiments were carried out batch wise, at $25^{\circ} \mathrm{C}$, using synthetic samples of $\mathrm{CV}$ prepared in distilled water. A stock solution of the CV containing $500 \mathrm{mg} / \mathrm{L}$ was used for the adsorption isotherm and kinetic studies. The equilibrium adsorption of dye was performed by shaking $0.2 \mathrm{~g}$ of adsorbent in $50 \mathrm{~mL}$ of dye solution, in an incubator shaker at $200 \mathrm{rpm}$ for $6 \mathrm{~h}$, after which, the mixture was centrifuged at $10,000 \mathrm{rpm}$ and $4^{\circ} \mathrm{C}$, for $10 \mathrm{~min}$. The supernatant was gently removed and the concentration of CV in the supernatant was determined using a UV-VIS spectrophotometer (Shimadzu Corp., Japan), by measuring the absorbance at a wavelength of $590 \mathrm{~nm}$. The experiment was repeated with varying adsorbent dosage $(0.1-0.5 \mathrm{~g} / 50 \mathrm{~mL}$ of CV solution), concentration of the CV (100 - $1000 \mathrm{mg} / \mathrm{L})$, and the $\mathrm{pH}(2$ - 10), in order to determine the effects of different adsorbent dosage, dye concentration, and $\mathrm{pH}$ on $\mathrm{CV}$ removal from the simulated waste water. All experimental runs were performed at $25^{\circ} \mathrm{C}$ in triplicate. The $\mathrm{MZ}$ with the highest adsorption capacity was used to assess suitable adsorption isotherms and kinetics.

Adsorption capacity was calculated from the data obtained from the adsorption studies by a mass-balance relationship (Equation (1)),

$$
q_{e}=\frac{\left(C_{o}-C_{e}\right)}{m} \times V
$$

where, $q_{e}$ is the amount of dye adsorbed at equilibrium $(\mathrm{mg} / \mathrm{g}), V$ is the volume of the solution $(\mathrm{mL}), m$ is the mass of the adsorbent (g), $c_{o}$ and $c_{e}$ are the initial and equilibrium concentrations of the dye (mg/L), respectively. 


\subsection{Adsorption Isotherms}

Equilibrium adsorption data are commonly described with isotherms. Classical adsorption isotherms of Langmuir and Freundlich [32] [33], were used to explain the relationship between the amount of CV dye adsorbed at equilibrium $\left(q_{e}\right)$ and the equilibrium concentration of the dye $\left(c_{e}\right)$, at constant temperature. The Langmuir adsorption isotherm, which proposed uniform absorbent surface activity and monolayer adsorption, with finite adsorbent active sites, is expressed as:

$$
q_{e}=\frac{Q_{L} K_{L} C_{e}}{1+K_{L} C_{e}} .
$$

By taking the reciprocal of Equation (2), its linearized form is given in Equation (3) as:

$$
\frac{C_{e}}{q_{e}}=\frac{1}{Q_{L} K_{L}}+\frac{C_{e}}{Q_{L}},
$$

where $q_{e}$ is the maximum amount of the $\mathrm{CV}$ dye adsorbed per mass of absorbent (mg/g), $c_{e}$ is the equilibrium concentration (mg/L), and $K_{L}$ is a Langmuir constant $(\mathrm{L} / \mathrm{mg})$ related to the affinity of the binding sites, with $Q_{L}$ being the limiting adsorption capacity (mg/g), when the MZ surface is saturated with the dye. $Q_{L}$ and $K_{L}$ were determined from the linear plot of $c_{e} / q_{e}$ versus $c_{e}$.

The Freundlich adsorption isotherm, which is often based on a heterogeneous surface adsorption, is given by Equation (4):

$$
q_{e}=K_{F} C_{e}^{1 / n},
$$

with the linearized form being presented in Equation (5):

$$
\ln q_{e}=\ln K_{F}+\frac{1}{n} \ln C_{e}
$$

where $q_{e}$ is the amount of dye adsorbed at equilibrium (mg/g), $c_{e}$ is the equilibrium concentration $(\mathrm{mg} / \mathrm{L})$, while $K_{F}$ and $n$ are the Freundlich model constants, whose values were obtained from the plot of Ln $q_{e}$ against Lnc $e_{e}$.

\subsection{Kinetic Studies}

Kinetic studies were performed to investigate the effects of contact time on the quantity of dye adsorbed, at a fixed initial dye concentration $(500 \mathrm{mg} / \mathrm{L})$, by adding $50 \mathrm{~mL}$ of the dye solution to $0.2 \mathrm{~g}$ of $\mathrm{MZ}$. The mixture was shaken in an incubator shaker at $200 \mathrm{rpm}$ and $25^{\circ} \mathrm{C}$, while samples were taken periodically. The concentration of the adsorbed dye was determined at $590 \mathrm{~nm}$ wavelength, as described previously. The quantity of CV adsorbed $\left(q_{t}\right)$ at time $t$ was determined by Equation (6):

$$
q_{t}=\frac{C_{o}-C_{t}}{m} V
$$

where, $q_{t}$ is the amount of dye adsorbed at time $t(\mathrm{mg} / \mathrm{g}), V$ is the volume of the solution $(\mathrm{mL}), m$ is the mass of the adsorbent (g), $c_{o}$ and $c_{t}$ are the concentrations of the dye at initial $(t=0)$ and at time $t$, respectively. The rate constants were calculated by using the pseudo first-order, pseudo-second-order, and the Elovich equations [34] [35].

\section{Kinetic Models}

The pseudo-first-order expression is given in Equation (7) as:

$$
\log \left(q_{e}-q_{t}\right)=\log q_{e}-\frac{k_{1}}{2.303} t,
$$

where $q_{t}$ is the amount of adsorbed dye $(\mathrm{mg} / \mathrm{g})$ on the adsorbent at time $t$, and $k_{1}\left(\mathrm{~min}^{-1}\right)$ is the rate constant of the pseudo-first-order adsorption. From the intercept of a plot of $\log \left(q_{e}-q_{t}\right)$ versus $t, q_{e}$ and $k_{1}$ were determined.

The pseudo-second-order kinetic model is expressed in Equation (8) as: 


$$
\frac{t}{q_{t}}=\frac{1}{k_{2} q_{e}^{2}}+\frac{t}{q_{e}}
$$

where $k_{2}\left(\mathrm{~g} \cdot \mathrm{mg}^{-1} \cdot \mathrm{min}^{-1}\right)$ is the rate constant of pseudo-second-order kinetic. $k_{2}$ and $q_{e}$ were determined from the gradient and intercept of the plot $t / q_{t}$ versus $t$.

The initial adsorption rate $\left(h_{o}\right)$ is expressed in Equation (9) as:

$$
h_{o}=k_{2} q_{e}^{2} .
$$

The rate of adsorption of dye on the MZ surface decreases with time, without desorption of the products, due to increased adsorbent surface coverage. One of the most relevant models used for describing such phenomenon is the Elovich equation [36], given in Equation (10) as:

$$
q_{t}=b \ln (a b)+b \ln t,
$$

where $a$ and $b$ are the Elovich coefficients, which can be determined from the plot of $q_{t}$ against $\ln t$.

\section{Results and Discussion}

\subsection{Adsorbent Synthesis and Characterization}

The MZ was synthesized in a batch system, by direct fusion of FA, sodium hydroxide and magnetite nanoparticles, in a ratio of 1:1.5:y, respectively. Where $y$ represents $0.1,0.2,0.3,0.5,0.75$, while, the MZ produced at these ratios were represented as $\mathrm{MZ}_{1}, \mathrm{MZ}_{2}, \mathrm{MZ}_{3}, \mathrm{MZ}_{4}$, and $\mathrm{MZ}_{5}$, respectively. Another zeolite (Z) sample was synthesized from the FA, without the addition of magnetite particles, in order to assess the effects of magnetite on the affinity of zeolites adsorbent for $\mathrm{CV}$ dye adsorption. From the preliminary adsorption studies, $\mathrm{MZ}_{1}$ gave the optimum adsorption of CV dye; hence, it was characterized and used for further studies.

The surface morphology of the samples was examined using SEM, and the corresponding micrographs obtained, at 5000× magnification, are shown in Figure 2. In addition, elemental distribution of the samples was assessed with an electron dispersion x-ray spectroscopy (EDS). As shown in Table 1, the increase in the Fe content of the MZ may obviously be due to the presence of $\mathrm{Fe}^{2+} / \mathrm{Fe}^{3+}$ of the magnetite particles.

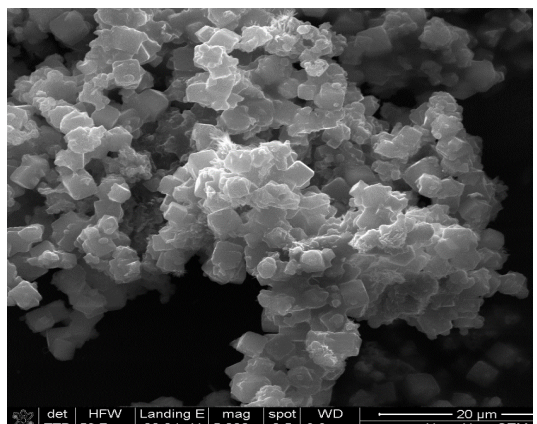

(a)

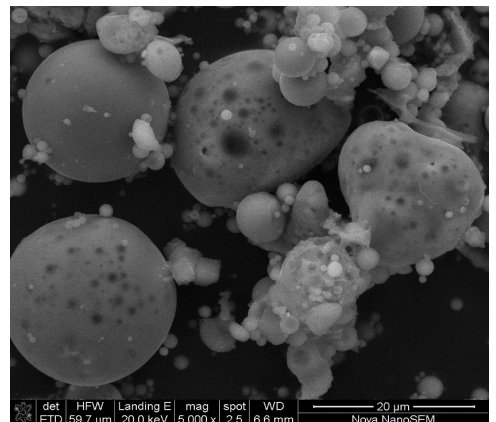

(b)

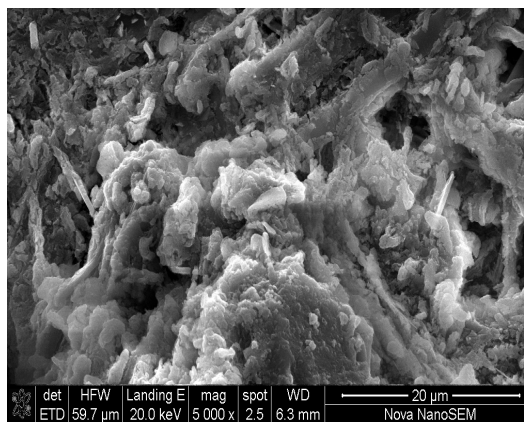

(c)

Figure 2. Scanning electron micrographs of FA (a), Z (b), and MZ (c).

Table 1. Elemental composition of FA, Z, and MZ adsorbents by EDS.

\begin{tabular}{cccc}
\hline Chemical Element & FA & Z & MZ \\
\hline C & 34.40 & 22.55 & 20.68 \\
O & 46.63 & 46.38 & 46.19 \\
$\mathrm{Na}$ & - & 9.97 & 23.83 \\
$\mathrm{Al}$ & 4.44 & 8.78 & 3.19 \\
$\mathrm{Si}$ & 19.04 & 10.44 & 3.09 \\
$\mathrm{Ca}$ & 2.25 & 1.29 & 0.22 \\
$\mathrm{Fe}$ & - & 0.59 & 2.80 \\
\hline
\end{tabular}


According to International Zeolite Association (IZA) and the International Mineralogical Association (IMA), zeolites with a Si/Al ratio of 1 - 1.5, in their framework, is classified as zeolite X [37]-[39]. Thus, a Si/Al ratio of 1.2 , obtained from the EDS analysis, showed that the synthesized zeolite, is zeolite $\mathrm{X}$, with pore sizes from 0.45 $0.80 \mathrm{~nm}$.

Typical $\mathrm{N}_{2}$ adsorption/desorption isotherms for the synthesized zeolite (Z) and MZare shown in Figure 3. The isotherms show a type-4H hysteresis loop as characterized by the IUPAC, which is often associated with slit-shaped pores-the type that is mainly obtained with activated carbons [40] [41]. This hysteresis loop resulted from capillary condensation in the mesopores. The adsorption of $\mathrm{N}_{2}$ unto the adsorbents was generally slow. Forsample $\mathrm{Z}$, about $70 \%$ of the gas was adsorbed at $P / P_{O}$ between 0.9 and 1.0 while about $78 \%$ of MZpores were covered at $P / P_{O}$ between 0.8 and 1.0. Furthermore, $N_{2}$ adsorption increased with respect to increased surface area, with $\mathrm{MZ}$ recording the highest adsorption of $32.20 \mathrm{~cm}^{3} / \mathrm{g}$ at standard temperature and pressure. In observing that the two branches of a loop cannot satisfy the requirement of thermodynamic reversibility, this implied that some distinctive metastable states exist in the process of adsorption and desorption of the adsorbate. In addition, the slow rate of adsorption observed was due to the unexpectedly low BET surface area determined for these nanoparticles (Figure 4).

In order to further understand the adsorption capacity of the synthesized zeolites, a $t$-plot was generated using equation: $t=\left[13.99 /\left(0.034-\log \left(P / P_{O}\right)\right)\right]^{0.5}$, proposed by Harkins-Jura, to determine the micropore volume $\left(V_{\text {mic }}\right)$ and mesopore volume $\left(V_{\text {mes }}\right)$ as well as the external surface area (Figure 5). The $V_{\text {mic }}$ and $V_{\text {mes }}$ were obtained from the intercepts of the curves with the y-axis, with the thickness range: $3.5 \AA$ to $6 \AA$. Moreover, the BET and
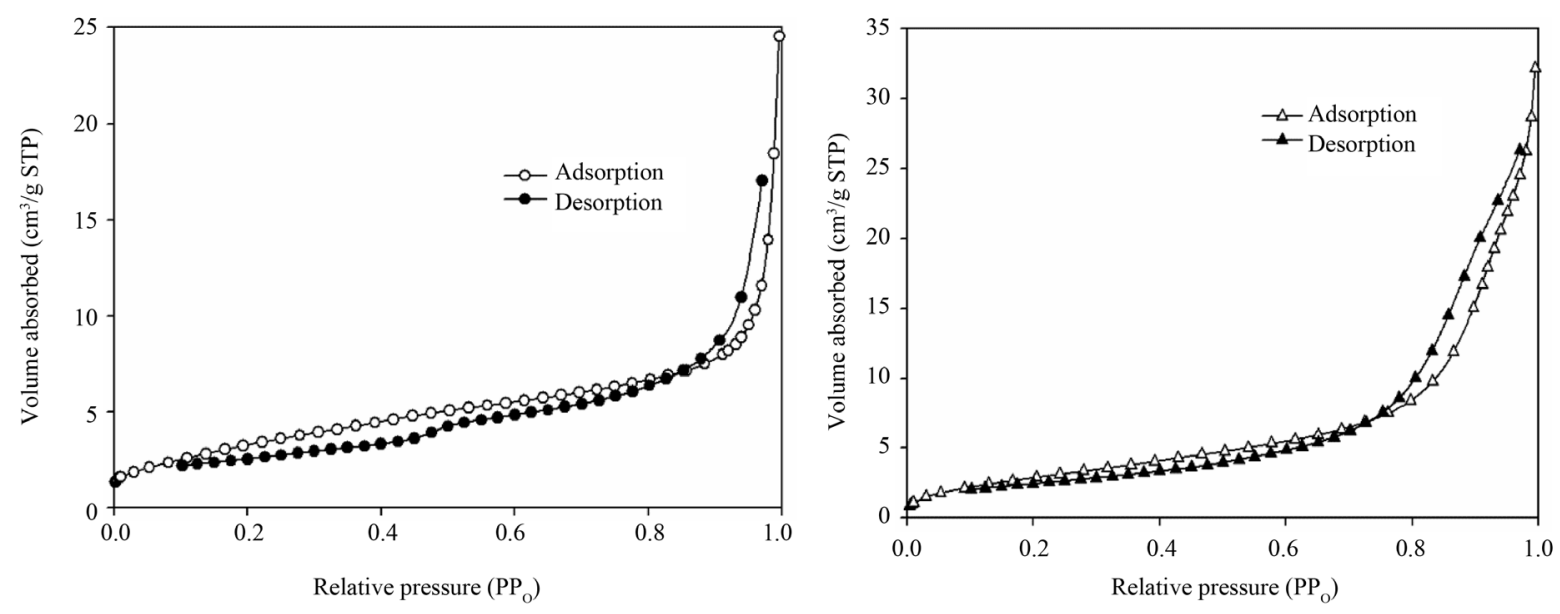

Figure 3. Nitrogen adsorption isotherms of zeolite (Z) and magnetic zeolite (MZ).

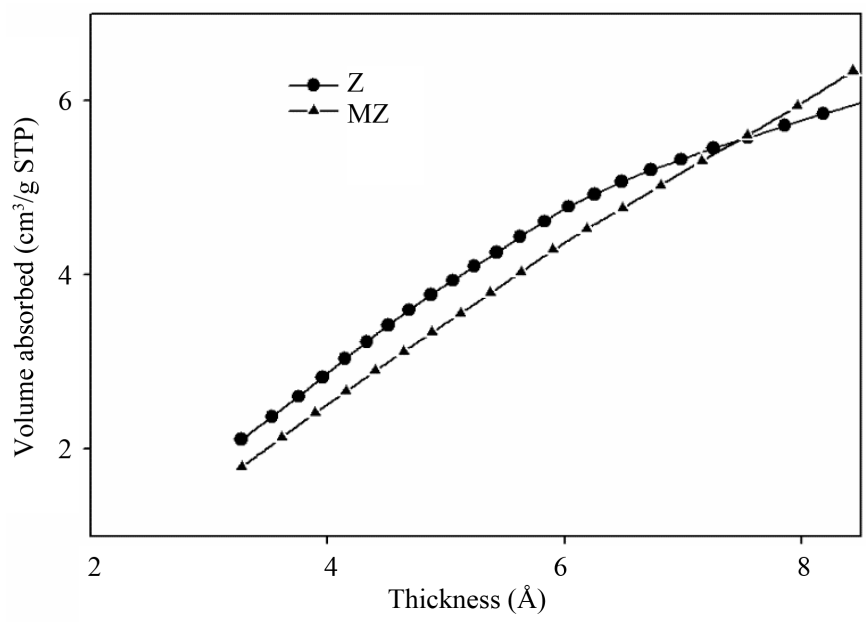

Figure 4. BET surface area plots for zeolite (Z) and magnetic zeolite (MZ). 
Langmuir surface areas were determined for the zeolite materials by measuring the quantity of $\mathrm{N}_{2}$ adsorbed at different relative pressures.

\subsection{Adsorption Studies}

Adsorption experiments were conducted to compare the adsorption capacity of FA, Z and the MZs produced at the different ratios of the magnetite particles. The results presented in Figure 6 showed that the addition of magnetite enhanced the adsorption capacity of zeolites adsorbent. Sample containing the least amount of the magnetite demonstrated the highest capacity for CV dye adsorption. However, the dye adsorptive capacity decreased slightly with the increased magnetite ratio in the mixture. Such phenomenon has been observed previously [30]. Recently, many studies have proposed the use of graphene magnetic nanoparticles and other magnetically incrusted particles in adsorption processes, particularly for the adsorption of organic compounds [42][44].

The effects of adsorbent dosage and $\mathrm{pH}$ of CV dye solution, in addition to different dye concentrations, on adsorption, were evaluated. It was observed that adsorption was nearly constant, even at low adsorbent dosage (Figure 7). This could be as a result of high surface area of the adsorbent. However, CV adsorption was significantly affected at low $\mathrm{pH}$ value below 4 (Figure 8), while equilibrium adsorption was maintained at $\mathrm{pH}$ values between 6 and 10. This phenomenon had earlier being observed [9] [45]. The decreased in the $\mathrm{pH}$ of the solution led to a reduction of the negatively charged adsorbent sites, and an increase in the number of positively charged sites, which lowered the adsorption of positively charged dye cations. Moreover, dye adsorption increased with increasing concentration of the dye in solution (Figure 9), until equilibrium concentration was reached at 500 $\mathrm{mg} / \mathrm{L}$. This is an expected trend, until equilibrium adsorption is reached, when all the adsorbent active sites

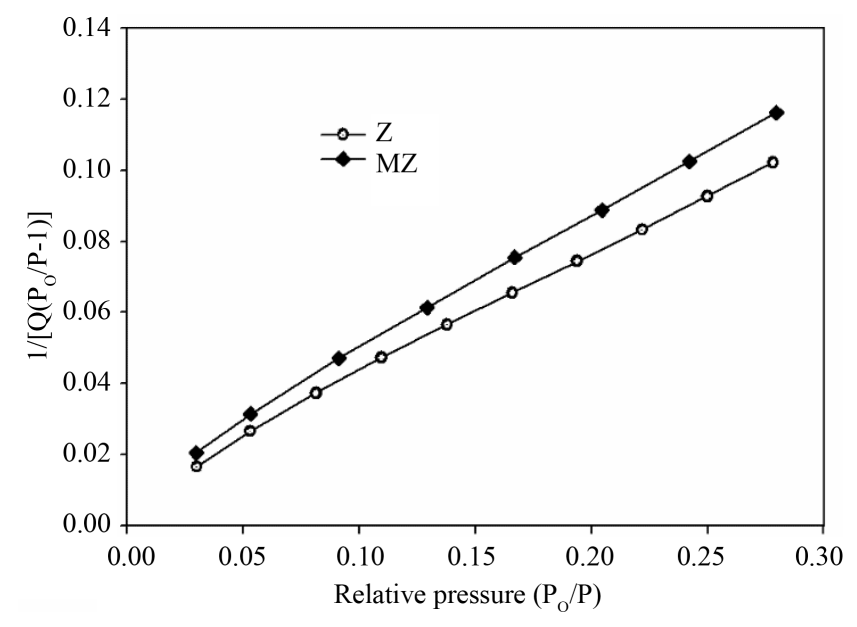

Figure 5. The $t$-plots for zeolite (Z) and magnetic zeolite (MZ).

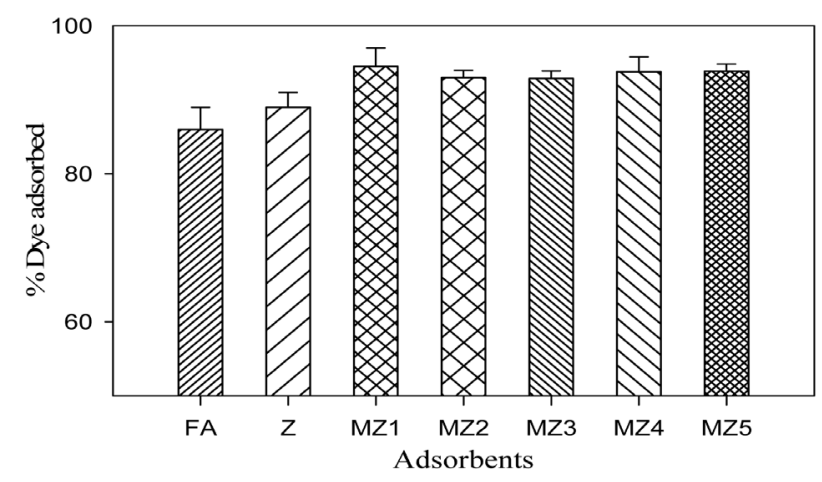

Figure 6. CV adsorption capacity of FA, Z, and MZ synthesized with different magnetite ratio. 


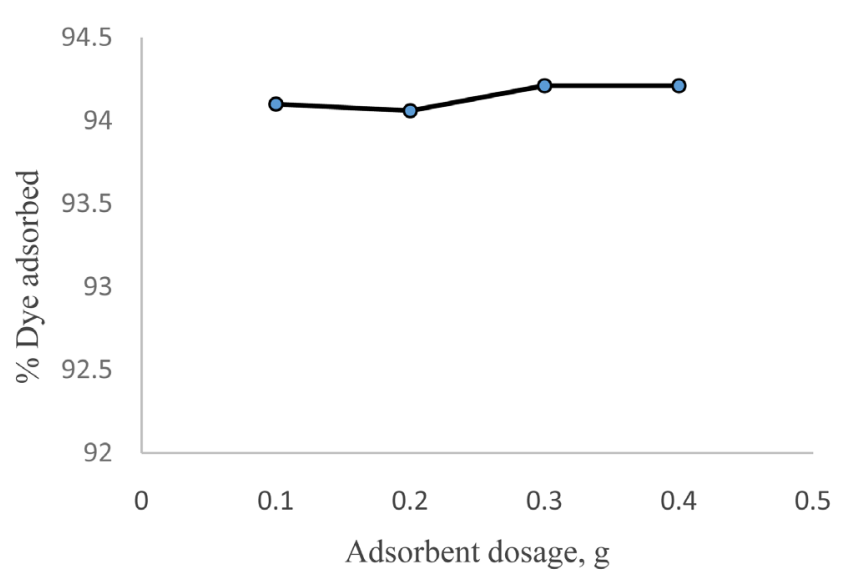

Figure 7. Effect of adsorbent dosage on the CV dye adsorption.

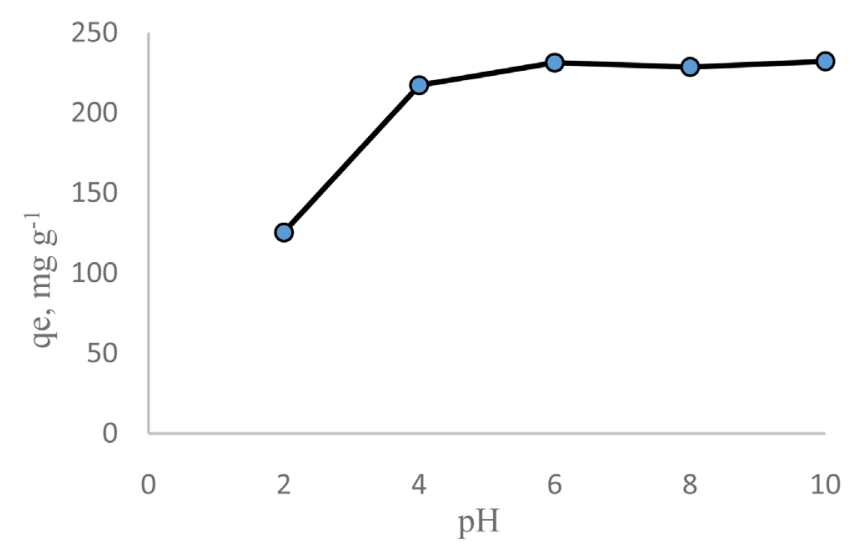

Figure 8. Effect of pH on CV dye adsorption onto MZ.

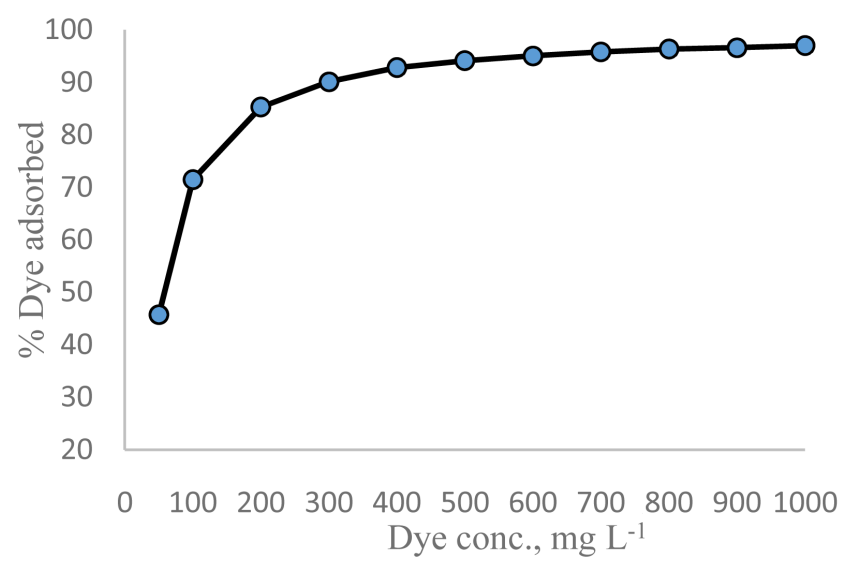

Figure 9. Effect of CV adsorbates concentration on adsorption.

would have been completely covered such that further increase in the adsorbate concentration has no effects on the adsorption.

\subsection{Adsorption Isotherms}

The adsorption isotherms of CV dye were explained by the classical Langmuir and Freundlich models [33]. Comparing the coefficients of correlation $\left(R^{2}\right)$ for the models (Figure 10 and Figure 11) and Table 2, Langmuir 


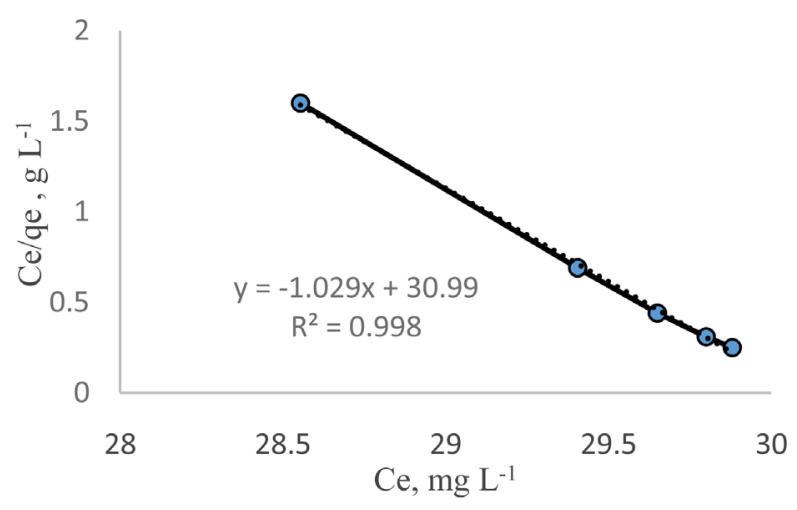

Figure 10. Langmuir plot for the adsorption of CV dye from aqueous solution.

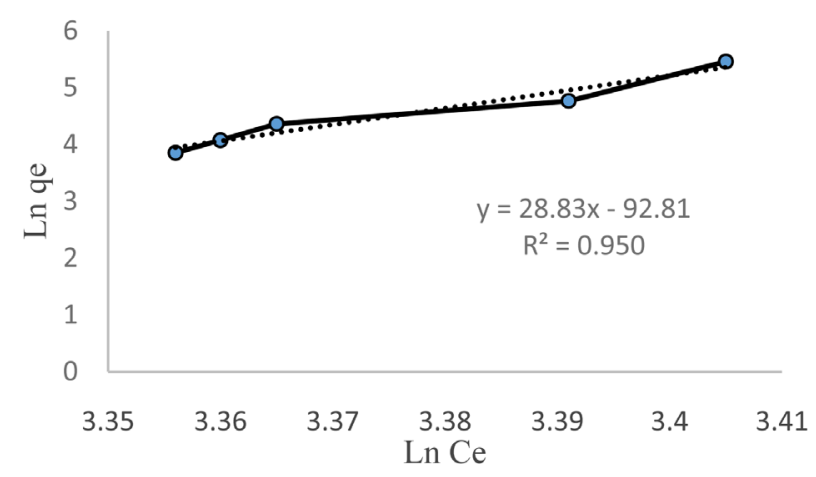

Figure 11. Freundlich isotherm for the adsorption of CV dye from aqueous solution.

Table 2. Isotherm and kinetics parameters obtained using the linear method for the adsorption of CV dye onto MZ.

\begin{tabular}{|c|c|c|c|c|c|c|c|c|c|}
\hline \multicolumn{4}{|c|}{ Isotherm } & \multicolumn{6}{|c|}{ Kinetics } \\
\hline \multicolumn{2}{|c|}{ Langmuir } & \multicolumn{2}{|c|}{ Freundlich } & \multicolumn{2}{|c|}{ Pseudo-first-order } & \multicolumn{2}{|c|}{ Pseudo-second-order } & \multicolumn{2}{|c|}{ Elovich } \\
\hline$Q_{L}$ & 0.9711 & $K_{F}$ & $4.894 \times 10^{-41}$ & $q_{e}(\mathrm{mg} / \mathrm{g})$ & 84.605 & $q_{e}(\mathrm{mg} / \mathrm{g})$ & 117.647 & $a$ & $2.18 \times 10^{4}$ \\
\hline$K_{L}$ & 0.03320 & $n$ & 0.03468 & $k_{1}\left(\min ^{-1}\right)$ & 0.3518 & $k_{2}(\mathrm{~g} / \mathrm{mg} / \mathrm{min})$ & 0.018 & $b$ & 7.414 \\
\hline \multirow[t]{2}{*}{$R^{2}$} & 9986 & $R^{2}$ & 0.9507 & $R^{2}$ & 0.9402 & $h_{o}(\mathrm{mg} / \mathrm{g} / \mathrm{min})$ & 249.135 & $R^{2}$ & 0.7027 \\
\hline & & & & & & $R^{2}$ & 0.9999 & & \\
\hline
\end{tabular}

gave a better fit of the experimental results.

The Langmuir model assumes monolayer CV dye adsorption onto homogeneous MZ surface with finite number of identical sites. The Langmuir constant $\left(K_{L}\right)$ and the limiting adsorption capacity $\left(Q_{L}\right)$ when the MZ surface is fully covered with the CV dye are $0.0332 \mathrm{~L} / \mathrm{mg}$ and $0.9711 \mathrm{mg} / \mathrm{g}$, respectively.

\subsection{Adsorption Kinetics}

The kinetics of CV dye adsorption onto MZ was investigated, and experimental results were modelled using pseudo-first-order, pseudo-second order, and Elovich equations. Kinetic study is invaluable in adsorption processes, as it helps in predicting the rate at which adsorbates are removed from the effluents being treated. The rate of adsorption can be affected by a couple of factors such as adsorbate-adsorbent affinity ratio; adsorbate concentration and adsorbent dosage-which were also investigated in this study; thermodynamics; etc. CV dye adsorption increased exponentially to equilibrium adsorption point in 10 mins (Figure 12), removing about 95\% of the dye from solution. This is one of the highest adsorption rates for CV, compared to other studies on CV adsorption [5] [6] [46]. It must be noted, however, that different dyes may have different adsorption equilibrium 
time, depending on their affinity for the particular adsorbents. Such affinity may be influenced by the chemical compositions and functional groups of the dyes, as well as, those of the adsorbents. Various equilibrium adsorption times have been reported for different basic dyes [46] [47]. Experimental results were fitted to the pseudo-first-order, pseudo-second-order kinetic models, as well as the Elovich equation. Figures 13-15, depicted the fitness of these kinetic models, with pseudo-second-order providing the best fit $\left(R^{2}=0.9999\right)$. The summary of the kinetic model parameters are presented in Table 2.

The pseudo-second-order kinetic model depends on the assumption that chemisorption is the rate-limiting step for the adsorption. In chemisorption, the CV dye ions attach to the MZ surface by forming a chemical bond and thus tend to find sites that maximize their coordination number with the surface [48]. The value of $h_{o}$ obtained for the pseudo-second-order kinetics was $249.135 \mathrm{mg} / \mathrm{g} / \mathrm{min}$, indicating a rapid adsorption of the CV dye onto the MZ particles. The quantity of the CV dye adsorbed at equilibrium per unit weight of the adsorbent $\left(q_{e}\right)$ was

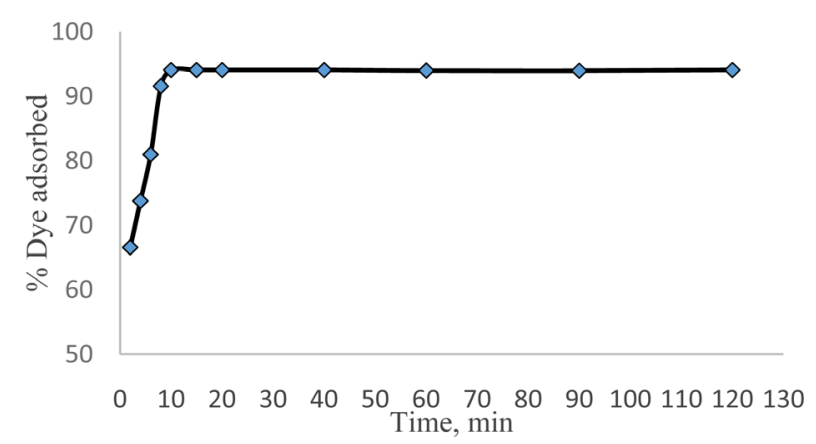

Figure 12. Absorption kinetics of CV onto MZ nanoparticles.

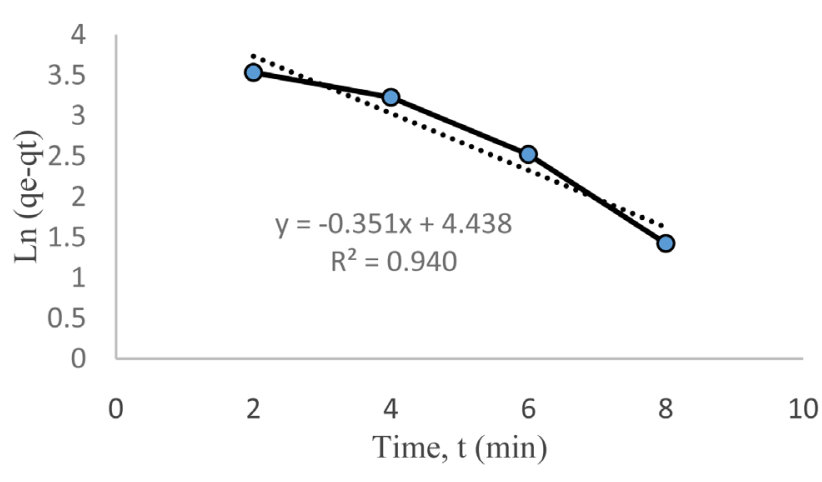

Figure 13. Pseudo-first-order kinetic model for CV dye adsorption onto MZ particles.

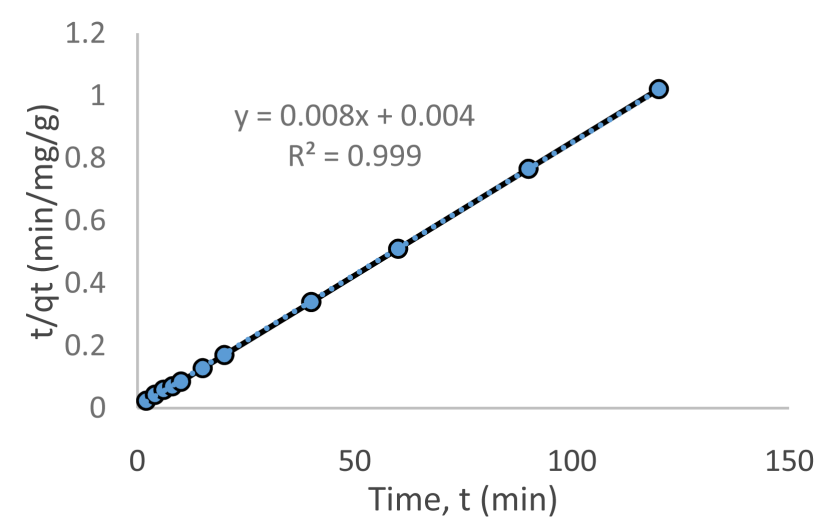

Figure 14. Pseudo-second-order kinetic model for CV dye adsorption onto MZ particles. 


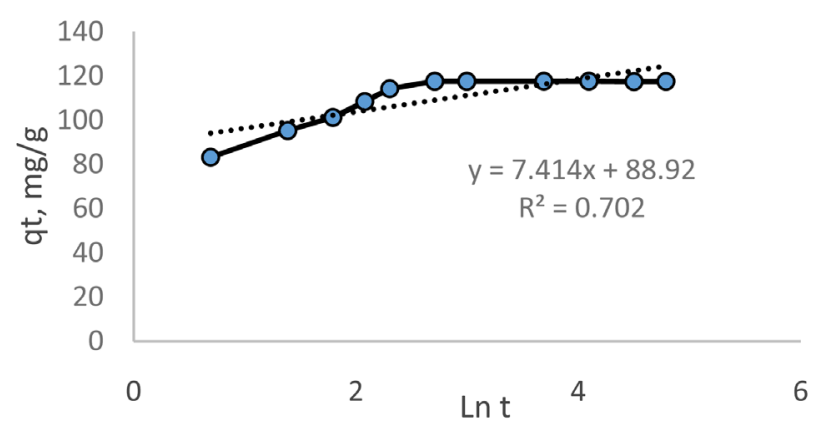

Figure 15. Elovich kinetic model for CV dye adsorption onto MZ particles.

$117.647 \mathrm{mg} / \mathrm{g}$ and the rate constant of pseudo-second-order adsorption $\left(k_{2}\right)$ was $0.018 \mathrm{~g} / \mathrm{mg} / \mathrm{min}$.

\section{Conclusion}

The synthesised MZ in this study demonstrated a high capacity for CV dye adsorption, removing 95\% of the dye at an equilibrium adsorption time of 10 mins, with an equilibrium concentration of $500 \mathrm{mg} / \mathrm{L}$. Varying adsorbent dosage did not show any significant effects on the adsorption of CV dye. However, the dye adsorption was significantly lowered at $\mathrm{pH}$ below 4, while equilibrium adsorption was maintained at $\mathrm{pH}$ values between 6 and 10 . The adsorption isotherm data were best explained by the Langmuir adsorption isotherm $\left(R^{2}=0.9986\right)$, while the adsorption kinetics was best fitted by the pseudo-second-order kinetic model $\left(R^{2}=0.9999\right)$. The application of MZs synthesised from inexpensive resources such as FA could ensure the sustainability and cost effectiveness of treating industrial effluents, containing basic dyes, especially effluent from textile industries.

\section{Acknowledgements}

Authors acknowledge the Cape Peninsula University of Technology for providing fund for this research.

\section{References}

[1] Textile Industry Poses Environmental Hazards. http://www.oecoteltiles.com

[2] Brigden, K., Labunska, I., Johnston, P and, Santillo, D. (2012) Organic Chemical and Heavy Metal Contaminants from Communal Wastewater Treatment Plants with Links to Textile Manufacturing, and in River Water Impacted by Wastewater from a Textile Dye Manufacturing Facility, in China. Technical Report, Greenpeace Research Laboratory, 7.

[3] Darbra, R.M., González, J.R., Casal, J., Àgueda, A., Capri, E., Fait, G., et al. (2012) Additives in the Textile Industry, in Global Risk-Based Management of Chemical Additives I: Production, Usage, and Environmental Occurence, In: Bilitewski, B., et al., Eds., The Handbook of Environmental Chemistry, Springer, Berlin, 83-107.

[4] Kant, R. (2011) Textile Dyeing Industry an Environmental Hazard. Natural Science, 4, 22-26. http://dx.doi.org/10.4236/ns.2012.41004

[5] Dahri, M.K., Kooh, M.R.R. and Lim, L.B. (2013) Removal of Methyl Violet 2B from Aqueous Solution Using Casuarina equisetifolia Needle. ISRN Environmental Chemistry, 2013, 1-8.

[6] Bertolini, T.C.R., Izidoro, J.C., Magdalena, C.P. and, Fungaro, D.A. (2013) Adsorption of Crystal Violet Dye from Aqueous Solution onto Zeolites from Coal Fly and Bottom Ashes. Orbital-The Electronic Journal of Chemistry, 5, 179-191.

[7] Adak, A., Bandyopadhyay, M. and, Pal, A. (2005) Removal of Crystal Violet Dye from Wastewater by Surfactant-Modified Alumina. Separation and Purification Technology, 44, 139-144. http://dx.doi.org/10.1016/j.seppur.2005.01.002

[8] Mittal, A., Mittal, J., Malviya, A., Kaur, D. and Gupta, V. (2010) Adsorption of Hazardous Dye Crystal Violet from Wastewater by Waste Materials. Journal of Colloid and Interface Science, 343, 463-473. http://dx.doi.org/10.1016/j.jcis.2009.11.060

[9] Garg, V., Gupta, R., Bala Yadav, Z. and Kumar, R. (2003) Dye Removal from Aqueous Solution by Adsorption on Treated Sawdust. Bioresource Technology, 89, 121-124. http://dx.doi.org/10.1016/S0960-8524(03)00058-0 
[10] Shi, B., Li, G., Wang, D., Feng, C. and Tang, H. (2007) Removal of Direct Dyes by Coagulation: The Performance of Preformed Polymeric Aluminum Species. Journal of Hazardous Materials, 143, 567-574. http://dx.doi.org/10.1016/j.jhazmat.2006.09.076

[11] Mohammed, M., Shitu, A. and Ibrahim, A. (2014) Removal of Methylene Blue Using Low Cost Adsorbent: A Review. Research Journal of Chemical Sciences, 4, 91-102.

[12] Ghoreishi, S. and Haghighi, R. (2003) Chemical Catalytic Reaction and Biological Oxidation for Treatment of NonBiodegradable Textile Effluent. Chemical Engineering Journal, 95, 163-169. http://dx.doi.org/10.1016/S1385-8947(03)00100-1

[13] Yang, Y., Centrone, A., Chen, L., Simeon, F., Alan Hatton, T. and Rutledge, G.C. (2011) Highly Porous Electrospun Polyvinylidene Fluoride (PVDF)-Based Carbon Fiber. Carbon, 49, 3395-3403. http://dx.doi.org/10.1016/j.carbon.2011.04.015

[14] Yamashita, J., Shioya, M., Kikutani, T. and Hashimoto, T. (2001) Activated Carbon Fibers and Films Derived from Poly (Vinylidene Fluoride). Carbon, 39, 207-214. http://dx.doi.org/10.1016/S0008-6223(00)00118-4

[15] Tan, I., Ahmad, A.L. and Hameed, B. (2008) Adsorption of Basic Dye Using Activated Carbon Prepared from Oil Palm Shell: Batch and Fixed Bed Studies. Desalination, 225, 13-28. http://dx.doi.org/10.1016/S0008-6223(00)00118-4

[16] Tan, I., Ahmad, A.L. and Hameed, B. (2008) Adsorption of Basic Dye on High-Surface-Area Activated Carbon Prepared from Coconut Husk: Equilibrium, Kinetic and Thermodynamic Studies. Journal of Hazardous Materials, 154, 337-346. http://dx.doi.org/10.1016/j.jhazmat.2007.10.031

[17] Rafatullah, M., Sulaiman, O., Hashim, R. and Ahmad, A. (2010) Adsorption of Methylene Blue on Low-Cost Adsorbents: A Review. Journal of Hazardous Materials, 177, 70-80. http://dx.doi.org/10.1016/j.jhazmat.2009.12.047

[18] Luna, F.M,T., Araújo, C.C., Veloso, C.B., Silva Jr., I.J., Azevedo, D.C. and Cavalcante Jr., C.L. (2011) Adsorption of Naphthalene and Pyrene from Isooctane Solutions on Commercial Activated Carbons. Adsorption, 17, 937-947. http://dx.doi.org/10.1007/s10450-011-9372-0

[19] Ania, C., Cabal, B., Parra, J., Arenillas, A., Arias, B. and Pis, J. (2008) Naphthalene Adsorption on Activated Carbons Using Solvents of Different Polarity. Adsorption, 14, 343-355. http://dx.doi.org/10.1007/s10450-007-9096-3

[20] Kaya, E.M.O., Özcan, A.S., Gök, O. and Özcan, A. (2013) Adsorption Kinetics and Isotherm Parameters of Naphthalene onto Natural- and Chemically Modified Bentonite from Aqueous Solutions. Adsorption, 19, 879-888. http://dx.doi.org/10.1007/s10450-013-9542-3

[21] Chang, C.F., Chang, C.Y., Chen, K.H., Tsai, W.T., Shie, J.L. and Chen, Y.H. (2004) Adsorption of Naphthalene on Zeolite from Aqueous Solution. Journal of Colloid and Interface Science, 277, 29-34. http://dx.doi.org/10.1016/j.jcis.2004.04.022

[22] Mahabadi, A.A., Hajabbasi, M., Khademi, H. and Kazemian, H. (2007) Soil Cadmium Stabilization Using an Iranian Natural Zeolite. Geoderma, 137, 388-393. http://dx.doi.org/10.1016/j.geoderma.2006.08.032

[23] Khalid, M., Joly, G., Renaud, A. and Magnoux, P. (2004) Removal of Phenol from Water by Adsorption Using Zeolites. Industrial \& Engineering Chemistry Research, 43, 5275-5280. http://dx.doi.org/10.1021/ie0400447

[24] Mainganye, D., Ojumu, T.V. and Petrik, L.F. (2013) Synthesis of Zeolites Na-P1 from South African Coal Fly Ash: Effect of Impeller Design and Agitation. Materials, 6, 2074-2089. http://dx.doi.org/10.3390/ma6052074

[25] Musyoka, N.M., Petrik, L.F., Gitari, W.M., Balfour, G. and Hums, E. (2012) Optimization of Hydrothermal Synthesis of Pure Phase Zeolite Na-P1 from South African Coal Fly Ashes. Journal of Environmental Science and Health, Part A, 47, 337-350. http://dx.doi.org/10.1080/10934529.2012.645779

[26] Du Plessis, P.W., Ojumu, T.V. and Petrik, L.F. (2013) Waste Minimization Protocols for the Process of Synthesizing Zeolites from South African Coal Fly Ash. Materials, 6, 1688-1703. http://dx.doi.org/10.3390/ma6051688

[27] Janoš, P., Buchtova, H. and Rýznarová, M. (2003) Sorption of Dyes from Aqueous Solutions onto Fly Ash. Water Research, 37, 4938-4944. http://dx.doi.org/10.1016/j.watres.2003.08.011

[28] Ahmaruzzaman, M. (2009) Role of Fly Ash in the Removal of Organic Pollutants from Wastewater. Energy \& Fuels, 23, 1494-1511. http://dx.doi.org/10.1021/ef8002697

[29] Alfadul, S.M. (2007) Using Magnetic Extractants for Removal of Pollutants from Water via Magnetic Filtration. PhD Dissertation, Oklahoma State University, Stillwater.

[30] Yamaura, M. and Fungaro, D.A. (2013) Synthesis and Characterization of Magnetic Adsorbent Prepared by Magnetite Nanoparticles and Zeolite from Coal Fly Ash. Journal of Materials Science, 48, 5093-5101. http://dx.doi.org/10.1007/s10853-013-7297-6

[31] Fungaro, D.A. and Magdalena, C.P. (2014) Counterion Effects on the Adsorption of Acid Orange 8 from Aqueous Solution onto HDTMA-Modified Nanozeolite from Fly Ash. Environment and Ecology Research, 2, 97-106.

[32] Adamson, A.W. and Gast, A.P. (1967) Physical Chemistry of Surfaces. Interscience, New York. 
[33] Foo, K. and Hameed, B. (2010) Insights into the Modeling of Adsorption Isotherm Systems. Chemical Engineering Journal, 156, 2-10. http://dx.doi.org/10.1016/j.cej.2009.09.013

[34] Ho, Y.S. and McKay, G. (1999) Pseudo-Second Order Model for Sorption Processes. Process Biochemistry, 34, 451465. http://dx.doi.org/10.1016/S0032-9592(98)00112-5

[35] Ho, Y.S. and McKay, G. (1998) Sorption of Dye from Aqueous Solution by Peat. Chemical Engineering Journal, 70, 115-124. http://dx.doi.org/10.1016/S0923-0467(98)00076-1

[36] Juang, R.S. and Chen, M.L. (1997) Application of the Elovich Equation to the Kinetics of Metal Sorption with Solvent-Impregnated Resins. Industrial \& Engineering Chemistry Research, 36, 813-820. http://dx.doi.org/10.1021/ie960351f

[37] Rivera-Garza, M., Olguın, M., Garcia-Sosa, I., Alcántara, D. and Rodrıguez-Fuentes, G. (2000) Silver Supported on Natural Mexican Zeolite as an Antibacterial Material. Microporous and Mesoporous Materials, 39, 431-444. http://dx.doi.org/10.1016/S1387-1811(00)00217-1

[38] Alberti, A., Armbruster, T., Artioli, G., Colella, C., Galli, E., Gice, J.D., et al. (1997) Recommended Nomenclature for Zeolite Minerals: Report of the Subcommittee on Zeolites of the International Mineralogical Association, Commission on New Minerals and Mineral Names. The Canadian Mineralogist, 35, 1571-1606.

[39] Tavolaro, A. and Drioli, E. (1999) Zeolite Membranes. Advanced Materials, 11, 975-996. http://dx.doi.org/10.1002/(SICI)1521-4095(199908)11:12<975::AID-ADMA975>3.0.CO;2-0

[40] Lippens, B.C. and De Boer, J. (1965) Studies on Pore Systems in Catalysts. Journal of Catalysis, 4, 319-323. http://dx.doi.org/10.1016/0021-9517(65)90307-6

[41] He, Y., Nivarthy, G., Eder, F., Seshan, K. and Lercher, J. (1998) Synthesis, Characterization and Catalytic Activity of the Pillared Molecular Sieve MCM-36. Microporous and Mesoporous Materials, 25, 207-224. http://dx.doi.org/10.1016/S1387-1811(98)00210-8

[42] Bruna, F., Celis, R., Real, M. and Cornejo, J. (2012) Organo/LDH Nanocomposite as an Adsorbent of Polycyclic Aromatic Hydrocarbons in Water and Soil-Water Systems. Journal of Hazardous Materials, 225, 74-80. http://dx.doi.org/10.1016/j.jhazmat.2012.04.064

[43] Vidal, C.B., Raulino, G.S.C., da Luz, A.D., da Luz, C., do Nascimento, R.F. and De Keukeleire, D. (2013) Experimental and Theoretical Approach to Multicomponent Adsorption of Selected Aromatics on Hydrophobically Modified Zeolite. Journal of Chemical \& Engineering Data, 59, 282-288. http://dx.doi.org/10.1021/je400780f

[44] Zhang, C., Wu, L., Cai, D., Zhang, C., Wang, N., Zhang, J., et al. (2013) Adsorption of Polycyclic Aromatic Hydrocarbons (Fluoranthene and Anthracenemethanol) by Functional Graphene Oxide and Removal by $\mathrm{pH}$ and Temperature-Sensitive Coagulation. ACS Applied Materials \& Interfaces, 5, 4783-4790. http://dx.doi.org/10.1021/am4002666

[45] Namasivayam, C., Prabha, D. and Kumutha, M. (1998) Removal of Direct Red and Acid Brilliant Blue by Adsorption on to Banana Pith. Bioresource Technology, 64, 77-79. http://dx.doi.org/10.1016/S0960-8524(97)86722-3

[46] Jayaraj, R., Suthakaran, A., Amala, S., Anbarasi, C., Selvamathan, S. and Prasath, P.M.D. (2012) Competitive Adsorption of Dyes (Crystal Violet, Methylene Blue, Malachite Green) on Chlor-Alkali Waste (Slurry). Journal of Chemical and Pharmaceutical Research, 4, 1251-1258.

[47] Singh, H. and Roohi, S. (2013) Removal of Basic Dyes from Aqueous Solutions Using Mustard Waste Ash and Buffalo Dung Ash. International Journal of Environmental Sciences, 3, 1711-1725.

[48] Ayanda, O.S., Fatoki, O.S, Adekola, F.A. and Ximba, B.J. (2013) Removal of Tributyltin from Shipyard Process Wastewater by Fly Ash, Activated Carbon and Fly Ash/Activated Carbon Composite: Adsorption Models and Kinetics. Journal of Chemical Technology and Biotechnology, 88, 2201-2208. http://dx.doi.org/10.1002/jctb.4088 